\title{
Effect of Instruction on Preventing Delayed Bleeding After Colorectal Polypectomy and Endoscopic Mucosal Resection
}

\section{Takuya Okugawa}

Hyogo College of Medicine: Hyogo Ika Daigaku

Tadayuki Oshima ( $\nabla$ t-oshima@hyo-med.ac.jp)

Division of Gastroenterology and Hepatology, Department of Internal Medicine, Hyogo College of

Medicine 1-1 Mukogawa-cho, Nishinomiya, Hyogo 663-8501, Japan https://orcid.org/0000-0001-6949932X

\section{Keisuke Nakai}

Hyogo College of Medicine: Hyogo Ika Daigaku

\section{Hirotsugu Eda}

Hyogo College of Medicine: Hyogo Ika Daigaku

\section{Akio Tamura}

Hyogo College of Medicine: Hyogo Ika Daigaku

\section{Ken Hara}

Hyogo College of Medicine: Hyogo Ika Daigaku

\section{Tomohiro Ogawa}

Hyogo College of Medicine: Hyogo Ika Daigaku

Tomoaki Kono

Hyogo College of Medicine: Hyogo Ika Daigaku

\section{Takashi Kondo}

Hyogo College of Medicine: Hyogo Ika Daigaku

\section{Katsuyuki Tozawa}

Hyogo College of Medicine: Hyogo Ika Daigaku

\section{Masashi Fukushima}

Hyogo College of Medicine: Hyogo Ika Daigaku

\section{Toshihiko Tomita}

Hyogo College of Medicine: Hyogo Ika Daigaku

Hirokazu Fukui

Hyogo College of Medicine: Hyogo Ika Daigaku

\section{Jiro Watari}

Hyogo College of Medicine: Hyogo Ika Daigaku Hiroto Miwa 


\section{Research article}

Keywords: colorectal polyps, delayed bleeding, antithrombotic agents, cold snare polypectomy, instruction

Posted Date: October 29th, 2020

DOl: https://doi.org/10.21203/rs.3.rs-97720/v1

License: @ (i) This work is licensed under a Creative Commons Attribution 4.0 International License. Read Full License

Version of Record: A version of this preprint was published at Journal of Clinical Medicine on March 1st, 2021. See the published version at https://doi.org/10.3390/jcm10050928. 


\section{Abstract}

Background: The frequency of delayed bleeding after colorectal polypectomy has been reported as 0.6 $2.8 \%$. With the increasing performance of polypectomy under continuous use of antithrombotic agents, care is required regarding delayed post-polypectomy bleeding. Better instruction to educate endoscopists is therefore needed. We aimed to evaluate the effect of instruction and factors associated with delayed bleeding after endoscopic colorectal polyp resection.

Methods: This single-center, retrospective study was performed to assess instruction in checking complete hemostasis and risk factors for onset of delayed post-polypectomy bleeding. The incidence of delayed bleeding, comorbidities, and medications were evaluated from medical records. Characteristics of patients before and after instruction were compared. Univariate analysis and forward stepwise logistic regression analysis were performed to test the influence of factors in association with delayed postpolypectomy bleeding.

Results: A total of 3318 polyps in 1002 patients were evaluated. The before-instruction group comprised 1479 polyps in 458 patients and the after-instruction group comprised 1839 polyps in 544 patients. Polyp size, pedunculated type, polyp location, and rate of cold snare polypectomy did not differ between before and after instruction. Clip placement was significantly more common after instruction $(22.6 \%, 416 / 1839)$ than before $(9.7 \%, 144 / 1479, P<0.01)$. Delayed post-polypectomy bleeding occurred in $1.1 \%$ of cases before instruction, and $0.4 \%$ after instruction. Instruction significantly decreased delayed bleeding, particularly in cases with antithrombotic agents. Multivariate logistic regression analysis showed that hot polypectomy, clip placement, and use of antithrombotic agents were significant independent risk factors for delayed post-polypectomy bleeding even after instruction.

Conclusion: The rate of delayed bleeding significantly decreased after instruction to check for complete hemostasis. Even after instruction, delayed bleeding can still occur in cases with antithrombotic agents or hot polypectomy.

\section{Backgroud}

Endoscopic resection is an effective treatment for colorectal polyps to achieve en-bloc resection and prevent local recurrence or the development of cancers and mortality [1-4]. Indications for endoscopic treatment have broadened, even in high-risk conditions such as patients still receiving antithrombotic agents, which are seeing increasing use [5]. However, delayed post-polypectomy bleeding (DPPB) remains one of the major adverse events. The incidence of DPPB has not decreased in recent years due to the aging of society and the increased use of antithrombotic agents [6]. Mortality directly attributable to DPPB is scarce, but this event can be serious because of unpredictable onset often occurring after hospital discharge and requiring intensive management involving repeated colonoscopy, blood transfusion, hospitalization, and a few colectomies [7]. 
Previous studies have reported risk factors for DPPB of age, size, location, chronic kidney disease, liver cirrhosis, and use of antithrombotic agents $[6,8,9]$. Patients receiving antithrombotic agents are more prone to experience DPPB than those not taking these agents [6]. Management of antithrombotic use in patients undergoing polypectomy is an important issue in clinical practice. Cessation of antithrombotic agents before treatment is the easiest option, but increases the risk of thrombosis [10-12]. Clarifying what options are available to decrease the risk of DPPB even without cessation of antithrombotic agents after endoscopic polypectomy is therefore important.

Recently, cold snare polypectomy (CSP) has been reported as a safe procedure even in patients on antithrombotic medications $[7,13,14]$. However, no clinical studies comparing DPPB between CSP with or without clip placement. Additionally, although some reports have found no DPPB after CSP, this event still occurs under real-world clinical conditions, and whether prophylactic placement of clips is effective for preventing DPPB remains controversial [15-18]. Furthermore, no reports have clarified whether DPPB can be prevented by post-resection irrigation and inspection of the mucosal defect in the resection stump [19, 20], or by checking for complete hemostasis after polypectomy, although both steps are considered effective. These kinds of basic procedures are likely important for the prevention of DPPB. Accordingly, the present study was conducted to evaluate the effects of instruction in checking for complete hemostasis and to identify factors associated with colorectal DPPB.

\section{Methods}

\section{Study design, setting and participants}

We performed this retrospective cohort study in a single center to evaluate the effects of instruction in checking for complete hemostasis after colorectal polyp resection on DPPB rates. All cases of polypectomy and endoscopic mucosal resection were included in this study at Hyogo College of Medicine between January and December 2018. Written informed consent was obtained from all patients prior to endoscopic procedures. The study protocol conforms to the ethical guidelines of the World Medical Association Declaration of Helsinki as reflected in a prior approval by the institution's human research committee. The study was approved by the Ethics Committee/Institutional Review Board at Hyogo College of Medicine, Japan on May 8, 2020 (No.2413). The database of colonoscopies with polyp resection and medical records of patients were evaluated with respect to the patient- and polyp-related factors noted below.

\section{Interventions}

As the incidence DPPB was thought to be high in the first half of 2018, pictures and preserved videos were assessed when DPPB was identified. Inspection while taking pictures of mucosal defects after polypectomy had not been routinely performed in cases with DPPB, particularly after cold polypectomy. Doctors performing polypectomy were therefore clinically instructed to confirm complete hemostasis on June 18,2018 . The detailed instruction was to confirm hemostasis by inspecting and taking pictures of the mucosal defect at the resection stump after polypectomy. Irrigation with water to achieve pseudo- 
submucosal injection was recommended after CSP (Fig. 1) and addition of hemostatic clip placement after CSP was recommended.

\section{Primary outcome}

The primary outcome of this study was predefined as the effect of instruction on the frequency of DPPB. We also sub-analyzed the influence of instruction on treatment strategies and residual risk factors even after instruction. Patients were divided into two groups: before and after instruction group. The characteristics of patients and polyps before and after instruction were then compared. Cases with endoscopic submucosal dissection (ESD) and patients with familial adenomatous polyps (FAP) were excluded.

\section{Polyp resection procedure}

Colonoscopic polypectomy was performed using a normal electric video endoscope (PCF-H290ZI, PCFQ260AZI, CF-HQ290; Olympus, Tokyo, Japan), with carbon dioxide insufflation. All patients received $2 \mathrm{~L}$ of polyethylene glycol solution or 1.8-2.4 L of magnesium citrate solution in the morning on the day of the procedure. CSP was performed for small polyps ( $£ 10 \mathrm{~mm}$ in maximum diameter) using Captivator II (Boston Scientific Japan, Tokyo, Japan). Cold forceps polypectomy (CFP) was performed for small polyps ( $£ 4 \mathrm{~mm}$ in maximum diameter) using Radial Jaw4 Jumbo cold polypectomy forceps (Boston Scientific Japan, Tokyo, Japan).The same endoscopists that performed CSP used a B-wave (Xemex, Tokyo, Japan), Captivator II (Boston Scientific Japan, Tokyo, Japan) or SnareMaster (Boston Scientific Japan, Tokyo, Japan) to perform hot snare polypectomy (HSP). For endoscopic mucosal resection (EMR), normal saline was injected into the submucosa before excision. VIO 300D (ERBE Elektromedizin, Tübingen, Germany) was used as a power source, and all participant endoscopists used the same setting. Decisions on procedures for polyps 3-45 mm in size (i.e., application of HSP, EMR, CSP or CFP and decisions regarding clip placement for prophylaxis of PPB were made by the endoscopists in charge.

\section{Factors for assessment}

DPPB was defined as bleeding requiring endoscopic hemostasis and occurring between 24 hours and 28 days after the procedure. Risk factors were identified by comparisons between before and after instruction. Risk factors for DPPB were classified according to patient, polyp, and procedure. Patientrelated factors consisted of age, sex, comorbidities (cerebrovascular disease, diabetes mellitus, hemodialysis, hypertension and ischemic heart disease), number of polyps removed per patient, and use of antithrombotic agents (anticoagulants including warfarin and direct oral anticoagulants, antiplatelet drugs including aspirin, clopidogrel, and cilostazol). If medications were only used intermittently, the patient was not classified as a user. Antithrombotic agents were discontinued or changed based on guidelines established by the Japanese Gastroenterological Endoscopy Society [21, 22]. When antithrombotic agents were discontinued or changed based on the guidelines, the patient was still defined as taking antithrombotic agents. Polyp-related factors comprised size, gross morphology, and location of the polyp. Polyp size was measured in comparison to the resection devices and divided into 3 groups ( $<6$ 
$\mathrm{mm} ; 6-10 \mathrm{~mm}$; or ${ }^{3} 11 \mathrm{~mm}$ ). The gross morphologies of polyps were classified as either pedunculated or sessile type, according to the Paris classification [23]. Locations of polyps were defined as right-sided colon (cecum, ascending colon, and transverse colon) or left-sided colon (descending colon, sigmoid colon, and rectum). Procedure-related factors included resection methods (COLD: CSP and CFP; or HOT: HSP and EMR) and use of prophylactic clipping and hemostatic clipping. Endoscopist experience ( ${ }^{3} 10$ years) was also assessed between groups.

\section{Statistical analysis}

No data regarding preventive effects on DPPB with instruction were available. However a $1 \%$ decrease in DPPB from the reported incidence (1.4\%) [24] was estimated. Based on these criteria, 1399 polyps in each group were required to detect a $5 \%$ (two-sided) intergroup difference in the primary variable using the chisquare test. Considering a dropout rate of approximately $5 \%$ after randomization, we set a required total of 2940 polyps (1470 per group).

Patient-related, polyp-related, and procedure-related characteristics were compared using chi-square testing or Fisher's exact tests, and Mann-Whitney U tests, where appropriate. To determine risk factors associated with DPPB, we estimated the odds ratio (OR) and 95\% confidence interval (Cl). Univariate analysis and forward stepwise (likelihood ratio) logistic regression analysis were performed to test the influence of several factors in association with DPPB. All reported $P$-values were two-sided and values less than 0.05 were considered statistically significant. SPSS 22.0 (SPSS Inc., Chicago, USA) was used for all statistical analyses.

\section{Results}

\section{Characteristics of patients}

A total of 1142 patients received colorectal polyp resection between January and December 2018. Of those 120 cases with ESD and 20 patients with FAP were excluded. A total of 3318 polyps in 1002 patients were evaluated and assigned to the two groups: 1479 polyps in 458 patients before instruction, and 1839 polyps in 544 patients after instruction (Fig. 2). After instruction, the rate of taking pictures of mucosal defects after polypectomy increased from $71.6 \%$ to $93.6 \%$ on a per-polyp basis. Table 1 shows the background characteristics of patients before and after instruction. Among all cases, 207 patients $(20.7 \%)$ with 784 polyps $(23.6 \%)$ received antithrombotic agents. No significant differences between groups were seen regarding clinical features including age, sex, or baseline characteristics including use of antithrombotic agents, and number of polyps removed per patient. The incidence of background comorbidities did not differ before and after instruction. The experience of the endoscopist ( 10 years) in charge of polypectomy was significantly higher after instruction (before, $31.0 \% \mathrm{vs}$. after, $38.6 \% ; P<0.05$ ). This difference was not planned in the original instruction.

\section{Characteristics of procedure}


The following assessments were all performed on a per-polyp basis. The characteristics of polyps and procedures were compared before and after instruction. Polyp size, pedunculated type, and polyp location did not differ between before and after instruction (Table 2). The rate of COLD was not significantly different between the two groups. Clip placement was significantly more common after instruction $(22.6 \%)$ than before $(9.7 \%, P<0.01)$.

\section{Incidence of DPPB}

Among the total cohort, DPPB occurred in 11 patients (5.3\%) and 24 polyps $(0.7 \%)$. Clip had been placed in 14 polyps (58.3\%) before DPPB. DPPB occurred at a median of 1 day (IQR, $1-3$ days) after treatment. The rate of DPPB was significantly lower after instruction $(0.4 \%)$ compared to before $(1.1 \% ; P<0.05)$ (Table 3 ). When considering the method of polypectomy, both COLD and HOT groups showed lower rates of DPPB after instruction, and the rate of DPPB in the COLD group was significantly lower after instruction $(0.4 \%$ vs. $0 \% ; P<0.05)$. In the COLD group, the incidence of DPPB was $0.2 \%$ in total and $0.4 \%$ before instruction. Three of four polyps with DPPB were in patients using antithrombotic agents before instruction, and no DPPB occurred after instruction. In the HOT group, the incidence of DPPB was $1.6 \%$ in total and tended to decease after instruction. Additionally, when considering the use of antithrombotic agents, the rate of DPPB with antithrombotic agents was significantly lower after instruction $(2.6 \%$ vs. $0.5 \%, P<0.05)$. On the other hand, the rate of DPPB without antithrombotic agents did not differ between before and after instruction.

\section{Factors related to DPPB}

All resected polyps were divided into bleeding and non-bleeding groups. Uni- and multivariate logistic regression analyses were performed to identify factors related to DPPB (Table 4). Univariate analysis showed that instruction was a significant preventive factor for DPPB. Furthermore, polyp size, pedunculated type, HOT, clip placement and use of antithrombotic agents were significant risk factors for DPPB. No significant differences in location (right-side colon) or endoscopist experience ( ${ }^{3} 10$ years) were seen between bleeding and non-bleeding groups. Multivariate logistic regression analysis showed that instruction was a significant independent preventive factor for DPPB. HOT, clip placement, and use of antithrombotic agents were significant independent risk factors for DPPB.

\section{Discussion}

This retrospective cohort study showed the importance of checking to ensure complete hemostasis by inspecting mucosal defects of the resection stump. Even after instruction, a small number of DPPB events still occurred after HSP. As clipping was an independent risk factor for DPPB, the location of clipping should be further considered to decrease DPPB. To the best of our knowledge, the present study is the first to show the importance of looking at the mucosal defect after polypectomy. Although the procedure time due to inspection of mucosal defect after polypectomy must have been prolonged, any DPPB that arises risks becoming serious because of unpredictable onset often occurring after hospital discharge and requiring intensive management [7]. 
In a recent meta-analysis of DPPB, the frequency was reported as $0.6-2.8 \%$ [25]. Cardiovascular disease, hypertension, polyp size (>10 mm), and polyps located in the right colon were indicated as significant risk factors for DPPB, whereas age, sex, alcohol use, smoking, diabetes, cerebrovascular disease, pedunculated morphology, and carcinoma histology were not significant risk factors for DPPB [25]. The use of antithrombotic agents is one of the risk factors for PPB and both immediate and delayed PPB occur in patients taking antithrombotic agents. In the present study, interestingly, the rate of DPPB in patients taking antithrombotic agents decreased significantly after instruction. However, the use of antithrombotic agents was still a significant risk factor for DPPB. These data indicate that inspection of the mucosal defect after polypectomy may be effective for patients taking antithrombotic agents, though it is important to note that the inspection cannot fully mitigate the risk of DPPB for these patients.

The experience of the endoscopist might also be associated with the incidence of DPPB. Less than 300 procedures or less than 1 year of experience were reported to correlate with higher rates of DPPB [26, 27]. Conversely, Kwon et al. did not find any association in DPPB rate comparing endoscopists practicing more or less than 10 years [28]. Similarly, Lee et al. found no difference in DPPB rate between procedures performed by fellows versus staff [29]. These data were similar to the present study, in that endoscopist experience did not affect the rate of DPPB. As a unified definition of endoscopic experience was lacking from these studies, whether endoscopic experience affects the incidence of DPPB remains unclear and further studies are warranted.

In a meta-analysis of hot and cold polypectomy, the rates of bleeding were $0.8 \%$ and $0 \%$ on a per-patient basis, and $0.4 \%$ vs. $0 \%$ on a per-polyp basis [30]. As indicated before, CSP is safer than HSP. In addition, in the present study, HOT was a significant risk factor for DPPB in multivariate analysis. As the incidence of bleeding was small, we need to be careful before concluding that the method of polypectomy affects the DPPB. However, the procedure itself must be one of the important factors contributing to the incidence of DPPB.

The incidence of clipping after cold polypectomy was $0-6 \%$ in previous reports [31-35]. Interestingly, all prospective data showed no DPPB after cold polypectomy, suggesting the safety of CSP. However, the incidence of DPPB after cold polypectomy in the present study could not be ignored before the intervention. The data indicated that we still need to be careful about DPPB even after cold polypectomy, with precise inspection of the mucosal defect. In the present study, no DPPB was seen after instruction in polyps after CSP, even with the increased rate of the procedure. As immediate PPB was higher after CSP compared to HSP in a meta-analysis [36], we also need to be careful regarding DPPB. However, when irrigation with water to make a pseudo-submucosal injection is done and we can confirm hemostasis after CSP by inspection of the mucosal defect after polypectomy, the situation can be considered safe and no DPPB occurs.

Although the rate of clipping increased after instruction in expectation of preventing DPPB in the present study, clipping was indeed an independent risk factor for DPPB. This was unexpected, but as recent reports have indicated, clipping does not appear effective in preventing DPPB [15]. One report showed 
that clipping after cold polypectomy was more likely to be used in the antithrombotic group. However, no significant difference in rate of DPPB was seen between lesions with and without clipping in that study [7]. One explanation might be related to the target lesions for clipping. Indications for clipping in the present study depended on the endoscopist in charge. When the risk of DPPB is considered high, clipping may be added. Therefore, lesions with clipping might already be at higher risk of DPPB, with clipping not proving effective for preventing DPPB. Another contributor would be ineffective clipping. The location of clipping should be reconsidered for preventing DPPB, because DPPB sometimes occurred next to the residual clips. Further studies are warranted to evaluate the effects of clipping on prevention of DPPB with careful inspection of mucosal defects.

Other than CSP and clipping, no other interventions have been assessed for the prevention of DPPB. In the present study, instruction on inspection of the mucosal defect proved preventive for DPPB, and no DPPB was seen after CSP even with continued use of antithrombotic agents. These data indicate that the intervention presented here would likely already have been enacted in clinical studies assessing the safety and efficacy of CSP, because they tried to avoid DPPB after CSP. Interestingly, no reports have shown the efficacy of clipping after CSP. A study by Kawamura et al. that was not permitted to add prophylactic hemostatic clipping after CSP for 5- to 9-mm polyps did not show any DPPB in 346 polyps [35]. The safety and efficacy of CSP can thus be achieved under strict inspection of mucosal defects with injection of water and without prophylactic clipping [31, 35].

Some limitations to the present study must be considered, and may require attention in further investigations. First, this was a retrospective study from a single institution. We therefore cannot exclude unrevealed confounding factors that affect DPPB. As our institution is a tertiary care center, the doctors would have encountered polypectomy procedures in different institutes earlier in their careers, and may have had different backgrounds and likely show the data of a multicenter study. Although performing a randomized study to examine the effects of inspection of mucosal defects may encounter ethical problems, prospective studies that assess the effect of irrigation of the mucosal defect after CSP might be possible. A second limitation was that the frequency of bleeding was low. As equipment for treatment differs between institutes and is improving quickly, a multicenter prospective study of a larger cohort would provide stronger evidence and reduce the risk of Berkson's bias.

\section{Conclusions}

The present study indicated that the rate of DPPB significantly decreased after instruction to check for complete hemostasis. Even after instruction was given, delayed bleeding was still encountered in cases with antithrombotic agents. Efforts to minimize events that may cause serious problems are still needed.

\section{Abbreviations}

DPPB: delayed post-polypectomy bleeding; CSP: cold snare polypectomy; ESD: endoscopic submucosal dissection; FAP: familial adenomatous polyps; CFP: cold forceps polypectomy; HSP: hot snare 
polypectomy; EMR: endoscopic mucosal resection; OR: odds ratio; Cl: confidence interval

\section{Declarations}

\section{Acknowledgements}

None.

\section{Authors' contributions}

Takuya Okugawa analyzed data, prepared Tables, and interpreted the results; Tadayuki Oshima designed the research, interpreted the results and drafted the manuscript; Keisuke Nakai, Hirotsugu Eda, Akio Tamura, Ken Hara, Tomoaki Kono, Takashi Kondo, Masashi Fukushima, Toshihiko Tomita, Hirokazu Fukui, and Jiro Watari interpreted the data and revised the manuscript; Hiroto Miwa designed the research and edited the manuscript.

\section{Funding}

This research did not receive any specific grant from funding agencies in the public, commercial, or notfor-profit sectors.

Availability of data and materials: All datasets used to support the findings of this study are available from the corresponding author upon reasonable request.

\section{Ethics approval and consent to participate}

All procedures performed in studies involving human participants were in accordance with the ethical standards of the institutional research committee and with the World Medical Association Declaration of Helsinki. The study was approved by the Ethics Committee/Institutional Review Board at Hyogo College of Medicine, Japan on May 8, 2020 (No.2413). The need for informed consent for study participants was waived as this was a retrospective study using deidentified data.

\section{Consent for publication}

Not applicable.

\section{Competing interests}

The authors declare that they have no competing interests.

\section{References}

1. Zauber AG, Winawer SJ, O'Brien MJ, Lansdorp-Vogelaar I, van Ballegooijen M, Hankey BF, Shi W, Bond JH, Schapiro M, Panish JF et al: Colonoscopic polypectomy and long-term prevention of 
colorectal-cancer deaths. N Engl J Med. 2012;366(8):687-96.

2. Loberg M, Kalager M, Holme O, Hoff G, Adami HO, Bretthauer M: Long-term colorectal-cancer mortality after adenoma removal. N Engl J Med. 2014;371(9):799-807.

3. Woodward T, Crook JE, Raimondo M, Wallace M: Improving complete EMR of colorectal neoplasia: a randomized trial comparing snares and injectate in the resection of large sessile colon polyps. Gastrointest Endosc. 2015;81(3):673-81.

4. Vleugels JLA, Hazewinkel Y, Fockens P, Dekker E: Natural history of diminutive and small colorectal polyps: a systematic literature review. Gastrointest Endosc. 2017;85(6):1169-76 e1.

5. Nijenhuis VJ, Bennaghmouch N, van Kuijk JP, Capodanno D, ten Berg JM: Antithrombotic treatment in patients undergoing transcatheter aortic valve implantation (TAVI). Thromb Haemost. 2015;113(4):674-85.

6. Shalman D, Gerson LB: Systematic review with meta-analysis: the risk of gastrointestinal haemorrhage post-polypectomy in patients receiving anti-platelet, anti-coagulant and/or thienopyridine medications. Aliment Pharmacol Ther. 2015;42(8):949-56.

7. Matsumoto M, Yoshii S, Shigesawa T, Dazai M, Onodera M, Kato M, Sakamoto N: Safety of Cold Polypectomy for Colorectal Polyps in Patients on Antithrombotic Medication. Digestion. 2018;97(1):76-81.

8. Hui AJ, Wong RM, Ching JY, Hung LC, Chung SC, Sung JJ: Risk of colonoscopic polypectomy bleeding with anticoagulants and antiplatelet agents: analysis of 1657 cases. Gastrointest Endosc. 2004;59(1):44-8.

9. Tsuruta S, Tominaga N, Ogata S, Tsuruoka N, Sakata Y, Shimoda R, Eguchi Y, Anzai K, Hara M, Fujimoto K: Risk Factors for Delayed Hemorrhage after Colonic Endoscopic Mucosal Resection in Patients Not on Antithrombotic Therapy: Retrospective Analysis of 3,844 Polyps of 1,660 Patients. Digestion. 2019;100(2):86-92.

10. Biondi-Zoccai GG, Lotrionte M, Agostoni P, Abbate A, Fusaro M, Burzotta F, Testa L, Sheiban I, Sangiorgi G: A systematic review and meta-analysis on the hazards of discontinuing or not adhering to aspirin among 50,279 patients at risk for coronary artery disease. Eur Heart J. 2006;27(22):266774.

11. Garcia DA, Regan S, Henault LE, Upadhyay A, Baker J, Othman M, Hylek EM: Risk of thromboembolism with short-term interruption of warfarin therapy. Arch Intern Med. 2008;168(1):639.

12. Sung JJ, Lau JY, Ching JY, Wu JC, Lee YT, Chiu PW, Leung VK, Wong VW, Chan FK: Continuation of low-dose aspirin therapy in peptic ulcer bleeding: a randomized trial. Ann Intern Med. 2010;152(1):19.

13. Horiuchi A, Nakayama Y, Kajiyama M, Tanaka N, Sano K, Graham DY: Removal of small colorectal polyps in anticoagulated patients: a prospective randomized comparison of cold snare and conventional polypectomy. Gastrointest Endosc. 2014;79(3):417-23. 
14. Arimoto J, Chiba H, Ashikari K, Fukui R, Anan H, Tachikawa J, Suto T, Kawano N, Niikura T, Kuwabara $\mathrm{H}$ et al: Safety of Cold Snare Polypectomy in Patients Receiving Treatment with Antithrombotic Agents. Dig Dis Sci. 2019;64(11):3247-55.

15. Forbes N, Frehlich L, James MT, Hilsden RJ, Kaplan GG, Wilson TA, Lorenzetti DL, Tate DJ, Bourke MJ, Heitman SJ: Routine Prophylactic Endoscopic Clipping Is Not Efficacious in the Prevention of Delayed Post-Polypectomy Bleeding: A Systematic Review and Meta-Analysis of Randomized Controlled Trials. J Can Assoc Gastroenterol. 2019;2(3):105-17.

16. Ayoub F, Westerveld DR, Forde JJ, Forsmark CE, Draganov PV, Yang D: Effect of prophylactic clip placement following endoscopic mucosal resection of large colorectal lesions on delayed polypectomy bleeding: A meta-analysis. World J Gastroenterol. 2019;25(18):2251-63.

17. Feagins LA, Smith AD, Kim D, Halai A, Duttala S, Chebaa B, Lunsford T, Vizuete J, Mara M, Mascarenhas R et al: Efficacy of Prophylactic Hemoclips in Prevention of Delayed Post-Polypectomy Bleeding in Patients With Large Colonic Polyps. Gastroenterology. 2019;157(4):967-76.e1.

18. Soh JS, Seo M, Kim KJ: Prophylactic clip application for large pedunculated polyps before snare polypectomy may decrease immediate postpolypectomy bleeding. BMC Gastroenterol. 2020;20(1):68.

19. Uraoka T, Ramberan H, Matsuda T, Fujii T, Yahagi N: Cold polypectomy techniques for diminutive polyps in the colorectum. Dig Endosc. 2014;26 Suppl 2:98-103.

20. Burgess NG, Bahin FF, Bourke MJ: Colonic polypectomy (with videos). Gastrointest Endosc. 2015;81(4):813-35.

21. Fujimoto K, Fujishiro M, Kato M, Higuchi K, Iwakiri R, Sakamoto C, Uchiyama S, Kashiwagi A, Ogawa $\mathrm{H}$, Murakami K et al: Guidelines for gastroenterological endoscopy in patients undergoing antithrombotic treatment. Dig Endosc. 2014;26(1):1-14.

22. Kato M, Uedo N, Hokimoto S, leko M, Higuchi K, Murakami K, Fujimoto K: Guidelines for Gastroenterological Endoscopy in Patients Undergoing Antithrombotic Treatment: 2017 Appendix on Anticoagulants Including Direct Oral Anticoagulants. Dig Endosc. 2018;30(4):433-40.

23. The Paris endoscopic classification of superficial neoplastic lesions: esophagus, stomach, and colon: November 30 to December 1, 2002. Gastrointest Endosc. 2003;58(6 Suppl):S3-43.

24. Oka S, Tanaka S, Kanao H, Ishikawa H, Watanabe T, Igarashi M, Saito Y, Ikematsu H, Kobayashi K, Inoue $Y$ et al: Current status in the occurrence of postoperative bleeding, perforation and residual/local recurrence during colonoscopic treatment in Japan. Dig Endosc. 2010;22(4):376-80.

25. Jaruvongvanich V, Prasitlumkum N, Assavapongpaiboon B, Suchartlikitwong S, Sanguankeo A, Upala S: Risk factors for delayed colonic post-polypectomy bleeding: a systematic review and metaanalysis. Int J Colorectal Dis. 2017;32(10):1399-406.

26. Bae GH, Jung JT, Kwon JG, Kim EY, Park JH, Seo JH, Kim JY: [Risk factors of delayed bleeding after colonoscopic polypectomy: case-control study]. Korean J Gastroenterol. 2012;59(6):423-7.

27. Choung BS, Kim SH, Ahn DS, Kwon DH, Koh KH, Sohn JY, Park WS, Kim IH, Lee SO, Lee ST et al: Incidence and risk factors of delayed postpolypectomy bleeding: a retrospective cohort study. J Clin 
Gastroenterol. 2014;48(9):784-9.

28. Kwon MJ, Kim YS, Bae SI, Park YI, Lee KJ, Min JH, Jo SY, Kim MY, Jung HJ, Jeong SY et al: Risk factors for delayed post-polypectomy bleeding. Intest Res. 2015;13(2):160-5.

29. Lee HS, Park JJ, Kim SU, Lee JE, Leem GL, Kim Y, Kim BK, Park JY, Kim DY, Ahn SH et al: Incidence and risk factors of delayed postpolypectomy bleeding in patients with chronic liver disease. Scand $J$ Gastroenterol. 2016;51(5):618-24.

30. Shinozaki S, Kobayashi Y, Hayashi Y, Sakamoto H, Lefor AK, Yamamoto H: Efficacy and safety of cold versus hot snare polypectomy for resecting small colorectal polyps: Systematic review and meta-analysis. Dig Endosc. 2018;30(5):592-9.

31. Ichise Y, Horiuchi A, Nakayama Y, Tanaka N: Prospective randomized comparison of cold snare polypectomy and conventional polypectomy for small colorectal polyps. Digestion. 2011;84(1):7881.

32. Repici A, Hassan C, Vitetta E, Ferrara E, Manes G, Gullotti G, Princiotta A, Dulbecco P, Gaffuri N, Bettoni $E$ et al: Safety of cold polypectomy for <10mm polyps at colonoscopy: a prospective multicenter study. Endoscopy. 2012;44(1):27-31.

33. Piraka C, Saeed A, Waljee AK, Pillai A, Stidham R, Elmunzer BJ: Cold snare polypectomy for nonpedunculated colon polyps greater than $1 \mathrm{~cm}$. Endosc Int Open. 2017;5(3):E184-E9.

34. Yamashina T, Fukuhara M, Maruo T, Tanke G, Marui S, Sada R, Taki M, Ohara Y, Sakamoto A, Henmi $S$ et al: Cold snare polypectomy reduced delayed postpolypectomy bleeding compared with conventional hot polypectomy: a propensity score-matching analysis. Endosc Int Open. 2017;5(7):E587-E94.

35. Kawamura T, Takeuchi Y, Asai S, Yokota I, Akamine E, Kato M, Akamatsu T, Tada K, Komeda Y, Iwatate $\mathrm{M}$ et al: A comparison of the resection rate for cold and hot snare polypectomy for 4-9 $\mathrm{mm}$ colorectal polyps: a multicentre randomised controlled trial (CRESCENT study). Gut. 2018;67(11):1950-7.

36. Jegadeesan R, Aziz M, Desai M, Sundararajan T, Gorrepati VS, Chandrasekar VT, Jayaraj M, Singh P, Saeed A, Rai T et al: Hot snare vs. cold snare polypectomy for endoscopic removal of 4 - $10 \mathrm{~mm}$ colorectal polyps during colonoscopy: a systematic review and meta-analysis of randomized controlled studies. Endosc Int Open. 2019;7(5):E708-E16.

\section{Tables}

Table 1 Characteristics of patients 


\begin{tabular}{|llll|}
\hline & $\begin{array}{l}\text { BEFORE } \\
(n=458)\end{array}$ & $\begin{array}{l}\text { AFTER } \\
(n=544)\end{array}$ & $P$ value \\
\hline Age, y & $70(61-77)$ & $69(61-77)$ & 0.88 \\
\hline Sex, male & $299(65.3)$ & $362(66.5)$ & 0.69 \\
\hline Antithrombotic agents & $94(20.5)$ & $113(20.8)$ & 0.94 \\
\hline Cerebrovascular disease & $20(4.4)$ & $24(4.4)$ & 1 \\
\hline Diabetes mellitus & $102(22.3)$ & $99(18.2)$ & 0.11 \\
\hline Hemodialysis & $9(2.0)$ & $16(2.9)$ & 0.42 \\
\hline Hypertension & $213(46.5)$ & $236(43.4)$ & 0.34 \\
\hline Ischemic heart disease & $14(3.1)$ & $13(2.4)$ & 0.56 \\
\hline Number of polyps removed per patient & $2(1-4)$ & $2(1-4)$ & 0.87 \\
\hline
\end{tabular}

$y$ : years.

Values are median (interquartile range) or $n(\%)$.

Table 2 Characteristics of polyps and procedures

\begin{tabular}{|rllll|}
\hline & $\begin{array}{l}\text { BEFORE } \\
(n=1479)\end{array}$ & $\begin{array}{l}\text { AFTER } \\
(n=1839)\end{array}$ & \\
\hline Size $\quad f 5 \mathrm{~mm}$ & $814(55.0)$ & $1074(58.4)$ & 0.09 \\
\hline $6-10 \mathrm{~mm}$ & $579(39.1)$ & $652(35.5)$ & \\
\hline $311 \mathrm{~mm}$ & $86(5.8)$ & $113(6.1)$ & \\
\hline Morphology; Ip & $55(3.7)$ & $62(3.4)$ & 0.63 \\
\hline Location; right-sided colon & $891(60.2)$ & $1111(60.4)$ & 0.94 \\
\hline Procedure; COLD & $944(63.8)$ & $1132(61.6)$ & 0.18 \\
\hline Clip & $144(9.7)$ & $416(22.6)$ & $<0.01$ \\
\hline
\end{tabular}

Values are $n(\%)$. 
Table 3 Incidence of delayed post-polypectomy bleeding

\begin{tabular}{|lllll|}
\hline & & BEFORE & AFTER & $P$ value \\
\hline All $(n=3318)$ & & $17 / 1479(1.1)$ & $7 / 1839(0.4)$ & $<0.05$ \\
\hline Procedure & COLD $(n=2076)$ & $4 / 944(0.4)$ & $0 / 1132(0)$ & $<0.05$ \\
\hline \multirow{2}{*}{ Antithrombotic agents } & HOT $(n=1242)$ & $13 / 535(2.4)$ & $7 / 707(1.0)$ & 0.07 \\
\cline { 2 - 5 } & $+(n=784)$ & $10 / 383(2.6)$ & $2 / 401(0.5)$ & $<0.05$ \\
\cline { 2 - 5 } & $-(n=2534)$ & $7 / 1096(0.6)$ & $5 / 1438(0.3)$ & 0.38 \\
\hline
\end{tabular}

Values are $n(\%)$.

Table 4 Factors related to delayed post-polypectomy bleeding 


\begin{tabular}{|c|c|c|c|c|c|}
\hline & & $\begin{array}{l}\text { Univariate } \\
\text { OR }(95 \% \mathrm{Cl})\end{array}$ & $\begin{array}{l}P \\
\text { value }\end{array}$ & $\begin{array}{l}\text { Multivariate }^{*} \\
\text { OR }(95 \% \mathrm{Cl})\end{array}$ & $\begin{array}{l}P \\
\text { value }\end{array}$ \\
\hline \multirow[t]{2}{*}{ Instruction } & BEFORE & 1.0 & & 1.0 & \\
\hline & AFTER & $\begin{array}{l}0.33(0.13- \\
0.80)\end{array}$ & $<0.05$ & $0.23(0.09-.57)$ & $<0.01$ \\
\hline \multirow[t]{3}{*}{ Size } & $£ 5 \mathrm{~mm}$ & 1.0 & & & \\
\hline & $6-10 \mathrm{~mm}$ & $\begin{array}{l}5.42(1.78- \\
16.5)\end{array}$ & $<0.01$ & & \\
\hline & з $11 \mathrm{~mm}$ & $\begin{array}{l}14.6(4.10- \\
52.3)\end{array}$ & $<0.01$ & & \\
\hline \multirow[t]{2}{*}{ Morphology } & non-Ip & 1.0 & & & \\
\hline & Ip & $\begin{array}{l}7.46(2.14- \\
21.1)\end{array}$ & $<0.01$ & & \\
\hline \multirow[t]{2}{*}{ Location } & Left-sided colon & 1.0 & & & \\
\hline & $\begin{array}{l}\text { Right-sided } \\
\text { colon }\end{array}$ & $\begin{array}{l}1.31(0.53- \\
3.57)\end{array}$ & 0.68 & & \\
\hline \multirow[t]{2}{*}{ Procedure } & COLD & 1.0 & & 1.0 & \\
\hline & НОT & $\begin{array}{l}8.47(2.83- \\
34.1)\end{array}$ & $<0.01$ & $\begin{array}{l}5.87(1.91- \\
18.03)\end{array}$ & $<0.01$ \\
\hline \multirow[t]{2}{*}{ Clip } & $(-)$ & 1.0 & & 1.0 & \\
\hline & $(+)$ & $\begin{array}{l}7.04(2.89- \\
17.8)\end{array}$ & $<0.01$ & $\begin{array}{l}5.55(2.32- \\
13.32)\end{array}$ & $<0.01$ \\
\hline \multirow{2}{*}{$\begin{array}{l}\text { Experience of } \\
\text { endoscopist }\end{array}$} & $<10 y$ & 1.0 & & & \\
\hline & $310 y$ & $\begin{array}{l}0.80(0.33- \\
2.02)\end{array}$ & 0.67 & & \\
\hline \multirow[t]{2}{*}{ Antithrombotic agents } & $(-)$ & 1.0 & & 1.0 & \\
\hline & $(+)$ & $\begin{array}{l}3.26(1.33- \\
7.98)\end{array}$ & $<0.01$ & $3.10(1.36-7.05)$ & $<0.01$ \\
\hline
\end{tabular}

Cl: confidence interval; OR: odds ratio; y: years.

${ }^{*}$ Forward stepwise (Likelihood ratio) logistic regression analysis.

Figures 
A

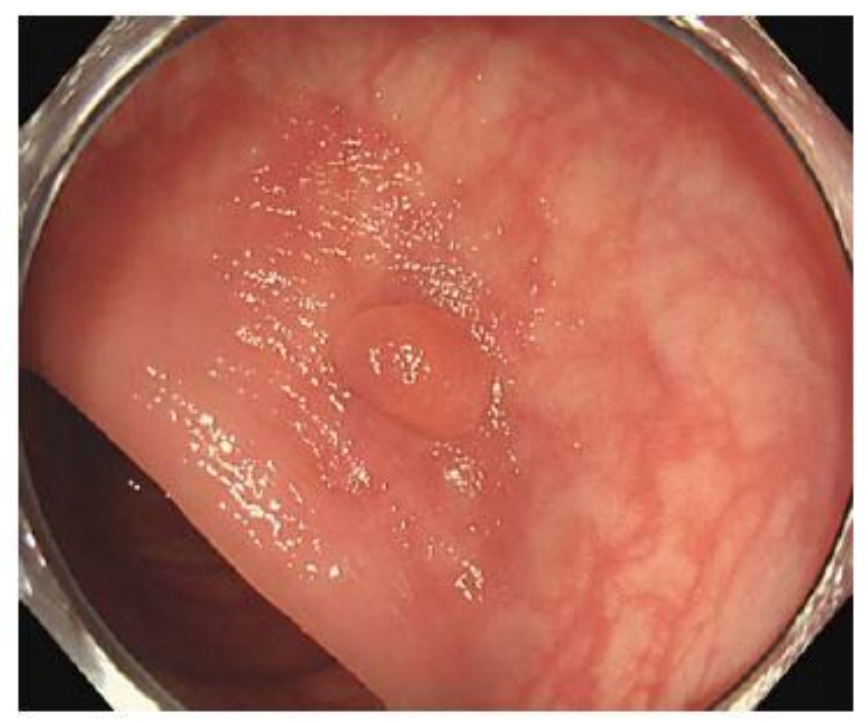

B

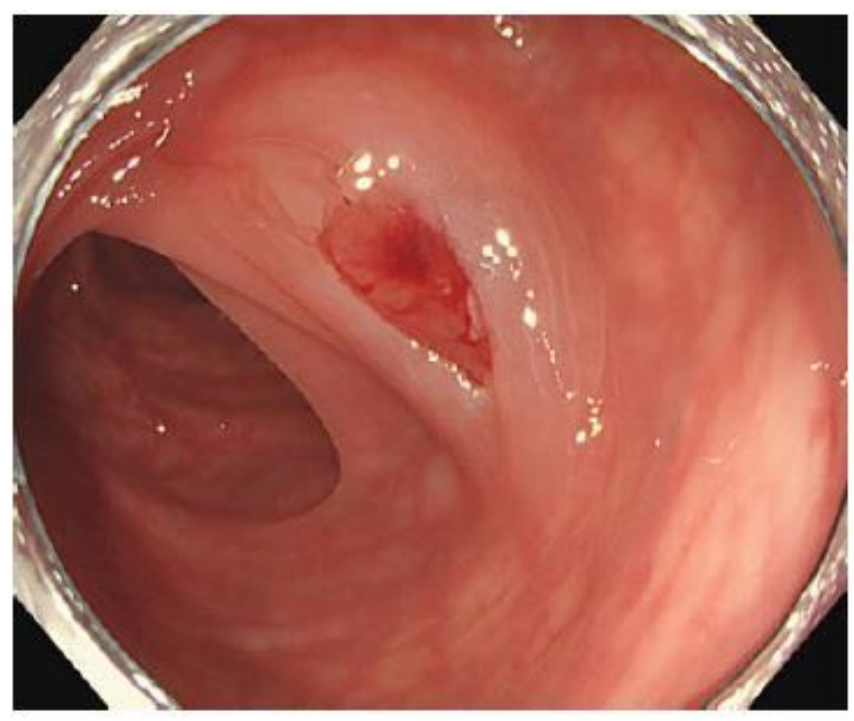

\section{Figure 1}

Representative pictures of cold snare polypectomy (a) A 5-mm polyp in the transverse colon. (b) The mucosal defect is expanded by water irrigation and no bleeding is evident. 


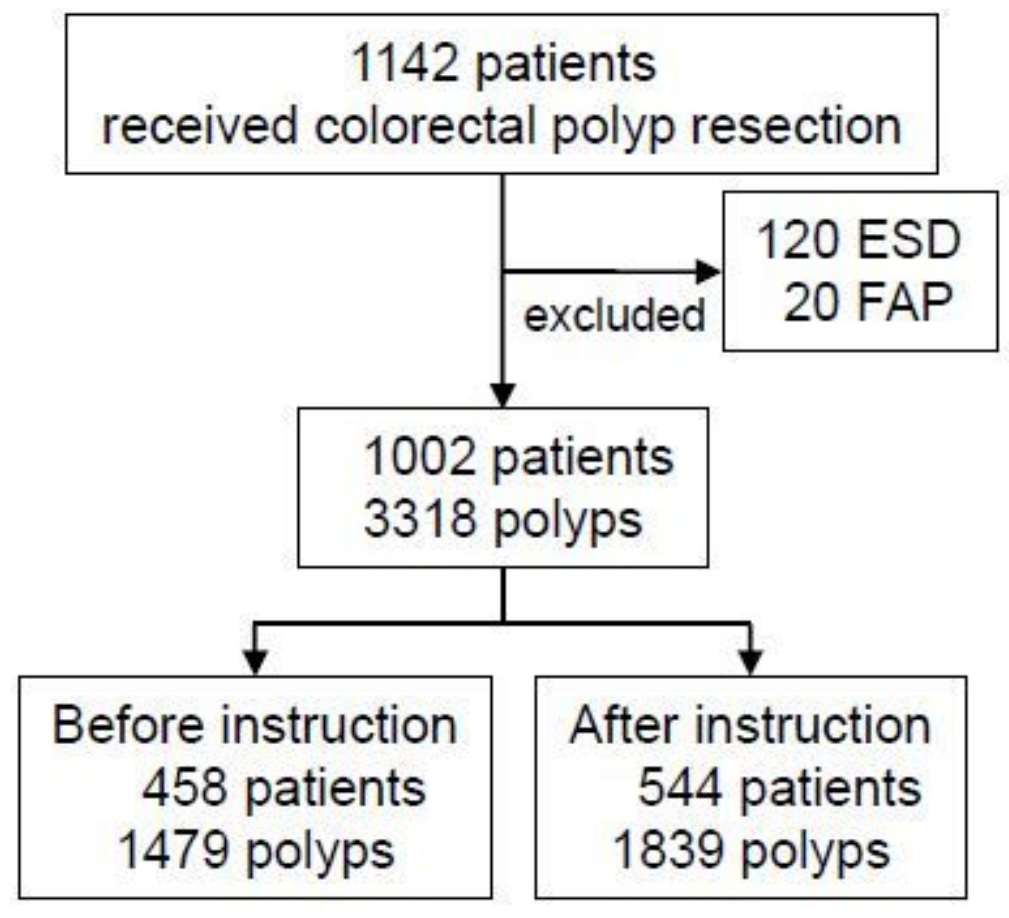

Figure 2

Flow diagram of patients and polyps ESD: endoscopic mucosal dissection; FAP: familial adenomatous polyposis 